\title{
Contracts for Dummies? The Performance of Investors in Contracts
}

\author{
for Difference ${ }^{\#}$
}

Adrian D. Lee

Shan Choy ${ }^{*}$

Latest draft: 19th March 2013

Accounting \& Finance, forthcoming

\begin{abstract}
Investors widely use contracts for difference (CFDs) to leverage and short sell underlying financial assets. We investigate the after cost performance of investors in Australian Securities Exchange listed share CFDs, and find that market order CFD trades earn small positive returns at the daily horizon, with negative returns reported for one month to one year horizons due to financing costs. Market orders also net sell positions, which suggests that investors use CFDs for shorting opportunities. Overall, we find that liquidity demanders in CFDs obtain favourable execution, which is inconsistent with the view that CFDs are used by naive individuals.
\end{abstract}

Keywords: Contracts for difference, CFDs, individual investors, trading costs.

JEL classification: G14

\footnotetext{
\# Adrian Lee thanks an anonymous referee, Kingsley Fong, Doug Foster, Michael Graham, Susanne Griebsch, Janice How, Daniel Smith and conference participants at the 3rd Conference on Financial Markets and Corporate Governance in Melbourne, Australia and the 2012 World Finance Conference in Rio de Janeiro, Brazil for helpful comments and suggestions. We thank Zhe Chen for research assistance.

- Corresponding author. Finance Discipline Group, University of Technology, Sydney, Sydney NSW 2000 Australia. Ph: +6129514 7765 Fax: +61 295147722 Email: adrian.lee@uts.edu.au

*Finance Discipline Group, University of Technology, Sydney, Sydney NSW 2000 Australia.
} 


\title{
Contracts for Dummies? The Performance of Investors in Contracts
}

\author{
for Difference
}

\begin{abstract}
Investors widely use contracts for difference (CFDs) to leverage and short sell underlying financial assets. We investigate the after cost performance of investors in Australian Securities Exchange listed share CFDs, and find that market order CFD trades earn small positive returns at the daily horizon, with negative returns reported for one month to one year horizons due to financing costs. Market orders also net sell positions, which suggests that investors use CFDs for shorting opportunities. Overall, we find that liquidity demanders in CFDs obtain favourable execution, which is inconsistent with the view that CFDs are used by naive individuals.
\end{abstract}




\section{Introduction}

We investigate the after cost performance of investors in exchange listed contracts for difference (hereafter CFDs) trades. CFDs are future-like derivatives which were originally sold to institutional investors in the 1990s. Offering the ability to leverage long and short positions on underlying financial assets at low cost, CFDs now enjoy global popularity with investors. Its popularity is also seen in the growth and substantial size of the CFD market, with Rhode (2010) estimating the UK CFD market alone being worth $£ 602$ billion in notional amounts in 2009 .

However, the complexity and risks of CFDs, together with the aggressiveness in which over-the-counter (OTC) CFD providers market their products to individual investors, have raised the attention of financial regulators such as the Australian Securities and Investment Commission (ASIC). ASIC has found that while CFD investors are confident in their investing, this confidence may not match their knowledge of CFDs - including knowledge of OTC provider pricing models, financing cost calculations and the operation of stop-loss orders (ASIC, 2010a). Subsequently, ASIC produced a CFD information booklet for individual investors (ASIC, 2010b) and rigorous product disclosure statement (PDS) guidelines for OTC providers (ASIC, 2011).

Despite the size and popularity of the CFD market and regulator concerns, to date there has been no academic research into the trading performance of investors in CFDs. ${ }^{1}$ The lack of research on investor trading in CFDs is perhaps not surprising as the great majority of CFD trades are made through the proprietary trading platforms of OTC providers. We overcome these data limitations by studying Australian Securities Exchange (ASX) listed CFDs. These exchange listed CFDs are a recent innovation in the CFD market and have a similar structure to OTC CFDs, with the main difference being trading transparency. As the dataset contains all trades and quotes of ASX-listed CFDs, we are thus able to shed some light on the trading performance of investors in a typically opaque market.

\footnotetext{
${ }^{1}$ Academic research into CFDs is also rare, with the notable exceptions of Brown et al. (2010) and Cacciotti and Michayluk (2012).
} 
Our study also contributes to the literature on investors of derivative instruments. While there is substantial literature on individual investor performance in stocks, which generally find that they perform poorly, ${ }^{2}$ studies on derivative performance are scarce. An exception is Bauer et al. (2009), which studies options trading on the Euronext Amsterdam by individual investors of a discount brokerage firm. Similar to the literature on stocks, they find that individuals incur substantial losses and attribute these losses to poor market timing and trading costs. Further, gambling (e.g. Kumar, 2009) and entertainment value appear to be the motivators for individuals to trade options.

We find that inclusive of the bid-ask spread, but before other costs, investor market order buys statistically outperform their sell CFD trades by 5.85 basis points per day over a one day holding period, with no statistically significant performance for longer holder periods of up to one year. This is despite the bid-ask spread on CFDs being 3.46 basis points more than when trading the underlying stock. When we take into account financing costs, the outperformance mark-to-market to the close and one day holding period becomes statistically insignificant, with negative returns for holding periods from one month to a year (with these losses driven almost entirely by financing costs).

When we split investor trades into small and large trade groups, we find that short-term performance is contained in both small (less than $\$ 10,000)$ and large trades $(\$ 20,000$ or more). This is inconsistent with the view that investors use small trades to earn lottery-like payoffs. CFD market orders also outperform market orders on the underlying stock for up to a one week horizon suggesting better trading performance than the average market order investor. We also find that investors show no market timing ability and that they consistently hold large net sell overnight positions with statistically significant and positive dollar trading profits and financing costs earned. This suggests that investors use CFDs for their ability to short. Further, we find that liquidity demanders in CFDs are not as unsophisticated as individual investors as regulators believe or found

\footnotetext{
${ }^{2}$ See, for example, Barber and Odean (2000) and Griffin et al. (2003) for the US; Oh et al. (2008) for Korea; Barber et al. (2009a) for Taiwan; and Fong et al. (2013) for Australia.
} 
to be in prior literature.

The structure of the paper is as follows: Section 2 provides the institutional background and related literature on CFDs. Section 3 discusses the data and the methodology used in our analysis. Section 4 reports our results and section 5 concludes.

\section{CFDs}

$\mathrm{CFDs}^{3}$ are a recent financial derivative that allows an investor to pay the counterparty the difference between the current value of the contract and the value when entering the contract, with reference to an underlying security price (e.g. commodities, indices or shares). If the current value of the contract is higher (lower) than the value when entering the contract, the long (short) position holder receives (forgoes) the difference. Similar to futures, CFDs provide investors with the ability to hold leveraged long or short positions over the underlying asset by only requiring the holder to provide a portion of the open position as margin. Also, depending on the broker, the CFD margin accounts may be interest bearing. For example, Commonwealth Securities currently offer the Reserve Bank of Australia (RBA) cash rate less $1.5 \%$ on cash balances in CFD margin accounts.

CFDs, however, differ to futures in a number of ways. First, CFDs do not have an expiry date but are instead mark-to-market daily to the underlying asset's settlement price. Second, financing costs which are implicit in futures prices are explicit in CFDs and paid or earned daily, based on the open position at the close of trade. Further, CFD holders receive or forgo dividends and other corporate actions through a cash adjustment to their account in order to mirror the underlying asset. This results in financing costs and dividends, unlike futures, not forming part of the pricing of CFDs.

While the leverage and explicit financing costs for CFDs appear similar to a strategy of using margin loans and share purchasing, it is worth noting the different tax treatments of the two products in Australia. The Australian Tax Office (2005) and Noble (2010) generally view the

\footnotetext{
${ }^{3}$ For a more comprehensive history of CFDs and detail of their structure, see Brown et al. (2010).
} 
realised gains or losses on CFDs (including dividends and financing costs) as income or a tax deduction, respectively. This contrasts with the taxation of shares in Australia where realised gains and losses are generally treated as capital gains or losses to the investor. ${ }^{4}$ This distinction is important as realised capital gains on shares held for more than one year are subject to a $50 \%$ discount on capital gains tax. Furthermore, financing costs in the form of interest on margin loans are tax deductible on income regardless if the gains or losses are realised throughout the financial year. As such, and given the lower before-tax financing costs of CFDs compared with margin loans, ${ }^{5}$ this suggests that CFDs are favourable to investors with holding periods of less than one year. We therefore focus our analysis of CFD trade performance to holding periods of one year or less.

\subsection{ASX-listed CFDs}

On $5^{\text {th }}$ November 2007, the ASX became the first exchange to list exchange-traded CFDs. At nearly the same time, the ASX delisted its individual share futures (ISFs) on ASX shares.

The ASX-listed CFDs are similar in specification to OTC CFDs, though with some key differences. First, trading occurs on the ASX trading system which uses an electronic limit order book. This differs to 'market maker model' OTC providers that provide indicative bid-ask quotes and market depth based on the underlying asset. Second, trades are clearing-house backed which reduces counterparty risk. The importance of such a feature to investors is clearly seen in the recent collapse of the OTC CFD provider, MF Global. Third, the ability of authorised participants to convert CFD contracts to the underlying asset through the exchange for physical facility ensures that the CFD price does not deviate too far from the underlying asset price during intraday trade. From a pricing perspective, this facility provides the link between the CFDs and its underlying

\footnotetext{
${ }^{4}$ Professional share traders who frequently trade shares are subject to income tax instead of capital gains tax, though we do not believe many individual investors would fall into this classification.

5 ASX-listed CFDs are 1.5\% p.a. above the RBA's overnight cash rate throughout our sample period, while margin loans are about 3-4\% p.a. above the RBA rate. Brown et al. (2010) cites margin lending rates being on average $3.4 \%$ higher over their November 2007 - December 2008 sample period.
} 
asset. A final difference relates to the assignment of designated price makers (DPMs) by the ASX, which provides liquidity to ASX-listed CFDs. According to the ASX-listed CFD glossary, ${ }^{6}$ DPMs receive incentives from the Exchange based on their success in trading ASX-listed CFDs. The presence of the DPMs in providing bid-ask quotes is important as this better enables us to differentiate between investor and DPM trades.

While the above differences between ASX-listed and OTC CFDs are important for CFD markets and pricing integrity, the predominance of OTC providers suggest that these features are not of high priority to investors. Indeed, in a recent survey of CFD traders in Australia, Investment Trends (2010) find that low commission and platform features were the main factors considered when switching providers. As the ASX-listed CFDs have similar costs to major OTC providers in trading Australian share CFDs, there is no a priori belief that investors using either exchange-listed or OTC providers would have different levels of sophistication. For example, at the time of writing, financing costs of ASX-listed CFDs amount to the RBA rate and $+/-1.5 \%$ for buys and sells, respectively. This compares with financing costs of the RBA rate $+/-2 \%$ and $+/-2.5 \%$ for the two largest OTC providers, CMC Markets and IG Markets, respectively. Brokerage rates were 0.11\% for ASX-listed CFDs traded through Commonwealth Securities, the largest ASX retail broker by trading volume, while CMC Markets and IG Markets both charged 0.1\%. Therefore, it appears the ASX-listed CFDs are at least cost competitive in comparison to its well established CFD competitors. $^{7}$

\section{Data and Methodology}

\subsection{Data}

We obtain trade and quote data on ASX-listed share CFDs and their underlying stocks from Thomson Reuters Tick History (TRTH) through the Securities Industry Research Centre of Asia-

\footnotetext{
${ }^{6}$ See: http://www.asx.com.au/products/glossary.htm.

${ }^{7}$ According to their respective corporate websites, CMC Markets (http://www.cmcmarkets.com.au/why-cmc/our-story) and IG Markets (www.igmarkets.com.au/cfd/about-us.html) began CFD operations in Australia in 2002.
} 
Pacific (SIRCA). Daily settlement prices and returns of the underlying stocks and index returns are obtained from the SIRCA Core Research Database (CRD) and TRTH, respectively.

We use the trade and quote data of all 71 listed share $\mathrm{CFDs}^{8}$ from the initial listing of the exchange-traded CFDs on the ASX from 5 November 2007 to 30 June 2010. The choice of underlying stocks for the CFDs is determined by the ASX, and represents the most liquid ASX stocks.

\subsection{Summary Statistics}

Table 1 presents descriptive statistics for trades on ASX-listed CFDs and their underlying stocks from 5 November 2007 to 30 June 2010. Statistics are shown for the entire sample as well as for a select sample of individual CFDs and their underlying stocks. ${ }^{9}$ As CFDs only trade during ASX's continuous trading hours, summary statistics for underlying stocks omit trading during the opening and closing auctions.

Trading volume in CFDs pale in comparison to the underlying stocks, as seen in the first three columns of Panel A in Table 1 that report the mean, median and standard deviation of the daily dollar trading volume. For our entire sample, the average CFD trading volume is $\$ 7.8$ million per day, while trading on the underlying stocks is 382 times larger at almost $\$ 3$ billion per day. The relatively light trading volume in CFDs is also seen with individual stocks. For example, BHP shares have 350 times larger trading volume than its CFD. The lack of volume indicates that there is still potential for the listed CFD market to grow.

Perhaps more surprising is the average trade sizes of CFDs and underlying stocks, as seen in the last three columns of Panel A in Table 1. The average daily trade size is $\$ 22,269$ for CFDs, which is larger than the $\$ 15,068$ trade size for underlying stocks. This suggests that algorithmic trading is dominant in the underlying stocks, despite its larger overall volume. The smaller underlying stock trade sizes also occurs with individual stocks, with Cochlear showing the largest

\footnotetext{
${ }^{8}$ We remove the Telstra Instalment Receipt from our analysis as we do not have reliable returns data on it.

${ }^{9}$ The full sample of individual CFD summary statistics is available from the authors upon request.
} 
trade size discrepancy with an average daily CFD trade size of $\$ 23,514$ compared with the underlying stock of just $\$ 3,482$. The lower medians for all CFDs and stocks suggest that most trades are smaller than the average trade size.

\section{[Insert Table 1 Here]}

While the lower trading volume in CFDs would deter institutional investors, the larger trade size in CFDs than those in the underlying stock requires some explanation. First, small investors such as retail investors incur minimum brokerage costs ${ }^{10}$ and therefore cannot cheaply break up trades as easily as institutional investors. Second, margin requirements mean that CFD investors are only required to put up at most $20 \%$ of the position as a margin. ${ }^{11}$ This means, at most, $\$ 4,454$ is required as a margin for the mean CFD trade of $\$ 22,269$, as shown in Panel A of Table 1 . The lower margin and minimum brokerage therefore creates an incentive for investors to make larger trades where possible. Further evidence of CFD trades being larger than those in the underlying stock is shown in Panel B of Table 1, which contains the percentage distribution of all CFDs and underlying stock trades in five trade size groups. The trade size cut-offs are nominal amounts. By count, the majority of CFD trades are $\$ 20,000$ or less, while about $60 \%$ of trades in the underlying stocks are less than $\$ 5,000$. However, by trade value, about $56 \%$ of CFD trades are in trade sizes of $\$ 10,000$ to $\$ 50,000$, while over $57 \%$ of trade values in underlying stocks are in trade sizes of more than $\$ 50,000$. This suggests that trading in CFDs is mainly focused on mid-sized trades, while underlying stock trades are either handled in small trades or completed using very large trades.

As further evidence that the CFD market has less algorithmic trading than the underlying stock market, for every trading day and every CFD/underlying stock, we report the difference in daily average mean and median times for quote changes and the daily number of quote changes. A quote change occurs when the best bid or ask price differs from the prior bid and ask on a day. If algorithmic trading is prevalent in CFDs, we expect that the quote change time and number of

\footnotetext{
${ }^{10}$ For example, discount retail broker Commonwealth Securities advertises CFD brokerage of the maximum of $\$ 14.95$ or $0.11 \%$ of trade value as of time of writing.

${ }^{11}$ In practice, ASX-listed CFD margin requirements are calculated in dollars per contract rather than in percentage terms, as with OTC CFDs.
} 
quotes to be statistically quicker and more frequent than that of the underlying stock. This is because CFDs are a derivative of the underlying stock and it is thus potentially possible for algorithms to arbitrage between the two using limit order management. Indeed, Foster and Liu (2011) show that there is vastly more order activity (and significantly less trading) in National Australia Bank warrants than in the underlying stock for periods from 2001 to 2010, which they attribute to algorithmic trading. In addition, the reported wider spreads in CFDs compared to the underlying stocks by Brown et al. (2010) would also allow for more movement of the bid-ask spread on CFDs by algorithmic traders. We report our findings for all 71 CFDs and daily average measures across all stocks in Appendix 1. We find that across all stocks, the mean and median average daily quote change in CFDs is 30.15 and 12.16 seconds slower than the underlying stock, respectively. This result is statistically significant at the $1 \%$ level. There are also, on average, 374.72 less quote changes by CFDs per day compared to the underlying stocks. Across individual stocks, we find no CFD that has statistically significant faster quote changes or more quote changes per day than the underlying stock. Combined with our evidence in Table 1 of larger trade sizes and lower volume in CFDs than in the underlying stock, this suggests that there is less algorithmic trading use by investors in CFDs compared to the underlying stocks.

\subsection{The Market Orders of Investor Trades}

As our data does not identify the traders, in order to analyse investor performance we must first infer which trades are made by investors and whether they are on the buy or sell side of the trade. Our strategy is to analyse buyer and seller initiated trades (i.e. market orders) as investor trades due to the institutional features of the CFD market and prior literature on limit order book markets.

Our first basis for using market orders is the presence of the designated price maker (DPM) approved by the ASX in the CFD market. As mentioned in Section 2.1, the ASX states that the role of the DPM is to 'provide liquidity in the ASX Listed CFD market'. DPMs also 'receive incentives 
from the Exchange based on their success in trading ASX Listed CFDs'. DPMs are also 'rebated the Open Interest Charge (OIC) as part of incentive arrangements with the ASX, face very low transaction fees, and as financial institutions should be able to access short-term interest rates close to the RBA target cash rate' (Brown et al., 2010, p.115). The specific role and numerous advantages of the DPMs over other investors suggest that DPMs are a major limit order/liquidity provider in the CFD market. ${ }^{12}$ While it is possible that the DPM may use buyer or seller initiated trades to correct any mispricing between the CFDs and its underlying asset, Brown et al. (2010) find that mispricing within reasonable transaction cost bounds is rare in ASX-listed CFDs and only occurs in illiquid CFDs. For this reason, focusing on market orders is a cleaner measure of investor performance as limit orders will contain both DPM and other investor trades.

A second institutional feature is that the CFD market during our sample period used SYCOM (Sydney Computerised Overnight Market, now ASX Trade24), while the underlying stock market used the separate ITS (Integrated Trading System, now ASX Trade). Brown et al. (2010) suggest that the lack of integration between the two systems makes it difficult to instantaneously arbitrage between platforms due to latency issues. Subsequently, other algorithmic traders are deterred from entering the CFD market. Our results on the slower quote changes in the CFD market in Appendix 1 also supports the lack of algorithmic trading. ${ }^{13}$ As such, market orders appear to be exclusively used by investors without the same algorithmic trading capabilities as participants holding the underlying stock.

Therefore, while it is clear that market orders are used by investors, the use of limit orders by investors may make it difficult to draw inferences about performance given that investors are on both sides of the trade. Indeed, Brown et al. (2010) find that during their sample period, 19.31\% of CFD trades are immediately followed by a trade in the underlying stock of the same size suggesting DPM hedging. As Brown et al. (2010) notes, 19.31\% is a conservative estimate of DPM

\footnotetext{
${ }^{12}$ It is also worth noting that in OTC CFDs using a 'market-maker' platform, the investor is unable to provide limit orders and instead must trade against the CFD provider's bid and ask quotes.

${ }^{13}$ ASIC (2010a) also finds little evidence that institutional investors make use of CFDs in Australia.
} 
trading as it does not take into account split trades in the CFD or underlying stock market. As such, there may be a portion of limit orders that are executed by investors and not the DPM. We thus rely on prior literature on limit order books to show that examining market orders is a reasonable proxy for investor performance.

Market orders are used for either trade urgency (e.g. Goettler et al., 2009; Roşu, 2009) or informed trading (e.g. Menkhoff et al., 2010). The use of market orders is therefore a conscious and realised trading decision by the investor to pay the bid-ask spread for immediate execution. Whether they are able to recuperate such costs from trading performance is an empirical issue. Also, as the spread is wider on CFDs than the underlying stock, as indicated by Brown et al. (2010), investors face an even larger hurdle in choosing to trade the CFD rather than the underlying stock when using market orders.

In contrast, the trade performance of limit order trades only partially measure skill and this is even more apparent in CFDs due to their wider spread. First, investors may use limit orders to provide liquidity, with the cost of such trading being that they bear non-execution risk and monitoring costs (e.g. Hollifield et al., 2006). In other words, whether a market order hits them is not determined by their trading skill. Second, even if limit orders are hit by an informed market order, the wider spread in the CFDs allows one to earn part of the spread by taking a market order in the underlying stock (e.g. execute a limit buy and immediately conduct a market sell in the underlying stock at a higher price). This hedging ability means a CFD limit order trade is not necessarily the mirror image of a CFD market order. The performance of CFD market order trades, however, is clearer as there is no hedging opportunity available to these investors.

The literature also finds that individual investors, who are purported to be unsophisticated and the main investors of CFDs using market or aggressive orders, exhibit poor short-term trading performance (e.g. Barber et al., 2009a; Linnainmaa, 2010; Fong et al., 2013). Linnainmaa (2010) shows that the market orders of individual investors earn negative returns to the closing price on the day, regardless if the trade is against individuals or institutions (while finding more negative returns 
against the latter). Fong et al. (2013) provides further evidence that the market orders of individual investors earn negative returns on the trading day and beyond - suggesting that the spread is a considerable trading cost. In particular, they find negative and statistically significant returns extending to 20 days for trades of discount retail brokers. Therefore, we expect negative short term returns for our sample of CFD market orders if investors are unsophisticated.

\subsection{Determining Market Orders}

To determine whether the trades are buyer or seller initiated, we first match every trade to the prevailing bid and ask quotes using the methodology of Ellis et al. (2000) and a zero-second time delay for trades as suggested by Henker and Wang (2006).

Similar to the methodology used in Hvidkjaer (2008) and Barber et al. (2009b), we use small signed trades to identify investor trades. However, while Barber et al. (2009b) attribute algorithmic trading and the breaking up of institutional trades to restricting their analysis up to pre2000, our CFD sample should not suffer such problems given the aforementioned lack of algorithmic trading in the CFD market.

\subsection{Measuring Investor Performance}

To measure investor performance using signed trades, we follow a methodology similar to Barber et al. (2009a) by using buys minus sells portfolios. However, we do not net the buy and sell trades but instead measure returns from the traded price rather than the day's close. ${ }^{14}$ This allows us to calculate a mark-to-market return from the traded price. The methodology we use is as follows:

1. Each day, buyer (seller) initiated trades are placed into the buy (sell) portfolio.

2. For all buy trades, the abnormal daily return for the buy portfolio on day $t$ over holding period $h$ is calculated as:

\footnotetext{
${ }^{14}$ Chen et al. (2000) also use a similar methodology in investigating buy-minus-sell trade performance, though they examine US mutual fund trades as inferred by their quarterly changes in stock holdings.
} 


$$
A R_{b, t}^{h}=\sum_{i=1}^{n} \frac{\operatorname{Vol}_{i, \mathrm{x}, t} \times P_{i, \mathrm{x}, t} \times R_{i, \mathrm{x}, t}^{h}}{\sum_{i=1}^{n} \operatorname{Vol}_{i, \mathrm{x}, t} \times P_{i, \mathrm{x}, t}}-R_{m, t}^{h}
$$

Where $\operatorname{Vol}_{i, x, t}$ is the number of CFD buy contracts opened for trade $x$ for CFD i. $P_{i, x, t}$ is the actual traded price of the CFD. $R_{i, x, t}^{h}$ is the next $h$ day's return of the CFD's underlying stock from the traded price where $h=0,1,5,20,127$ or 254 days. These intervals correspond with the return to the day's closing settlement price, next day, week, month, half-year and year returns. Using different holding periods of buys minus sells portfolios when the actual holding period of investors is unknown is commonly used in the literature as a way to determine whether short or long term trading performance exists (e.g. Chen et al., 2000; Barber et al., 2009a; Fong et al., 2013). $R_{m, t}^{h}$ is the return of the S\&P/ASX 200 Accumulation Index over the next $h$ days for holding periods of 1 day or more. ${ }^{15}$ An analogous measure is made for sell trades in the sell portfolio, $A R_{s, t}^{h}$. We also use the market capitalisation value weighted return of only the underlying stocks of CFDs as an alternative market benchmark.

3. The buy portfolio is subtracted from the sell portfolio to form the daily buys minus sells portfolio return, $B S_{t}^{h}$ :

$$
B S_{t}^{h}=A R_{b, t}^{h}-A R_{s, t}^{h}
$$

We then calculate the daily average $A R_{b, t}^{h}, A R_{s, t}^{h}$ and $B S_{t}^{h}$ measures to estimate investor trade performance. As such, a positive and statistically significant average $B S_{t}^{h}$ return means that investor buy trades outperform their sell trades, which infers superior trading performance over a given holding period. In addition, a positive (negative) and statistically significant $A R_{b, t}^{h}\left(A R_{s, t}^{h}\right)$ measure would suggest that investors are more skilled in buying (selling) CFDs compared with holding the market portfolio. For robustness, we also use characteristic-based benchmark alphas

\footnotetext{
${ }^{15}$ For trade to the settlement price, we do not adjust for the market index as this introduces noise into the return measure.
} 
following Pinnuck (2003).

\subsection{Incorporating Bid-Ask Spreads and Financing Costs}

We take into account the transaction costs of trading CFDs through measuring the bid-ask spreads and financing costs. As we use the traded price of buyer or seller initiated trades for our holding period return measures above, we implicitly incorporate the bid-ask spreads. However, we also separately measure the bid-ask spreads of CFDs to estimate the magnitude of CFD trading costs. For example, Brown et al. (2010) find the average time-weighted spreads on share CFDs to be approximately $0.50 \%$ higher than the underlying stock, which is a non-trivial result.

To estimate the daily value-weighted bid-ask spreads, we use the effective percentage half spread calculated as:

$$
\operatorname{Spread}_{i, t}=\sum_{x=1}^{n} \frac{\operatorname{Vol}_{i, x, t} \times p_{i, x, t} \frac{\left|p_{i, x, t}-m_{i, x, t}\right|}{m_{i, x, t}}}{\sum_{x=1}^{n} \operatorname{Vol}_{i, x, t} \times p_{i, x, t}}
$$

Where $\operatorname{Vol}_{i, x, t}$ is the number of CFD positions opened in trade $x, p_{i, x, t}$ is the traded price and $m_{i, x, t}$ is the prevailing midpoint quote as used to sign trades. A similar daily spread measure is also constructed for the underlying stocks. The daily spread on the buys or sells portfolios are estimated as the trade value-weighted daily spread of the individual CFDs. For CFD trades made on the underlying stock, spreads are calculated as the CFD trade value-weighted daily spread of the underlying individual stocks. This allows us to compare the trading costs on the CFDs to the underlying stocks.

Financing costs are in the form of a benchmark contract interest rate charge and the Open Interest Charge (OIC). Financing costs are paid or earned daily on the value of the open CFD position at the market's close. Contract interest plus OIC are paid if an investor holds a CFD long position, while contract interest less OIC is earned if an investor holds a short position in CFDs overnight. The OIC is fixed at $1.5 \%$ p.a. for both long and short positions throughout the sample 
period. The benchmark contract interest rate is the RBA's target overnight cash rate. As such, the OIC makes the calculated buys minus sells portfolio costly as, in essence, investors will lose $3 \%$ p.a. (1.5\% on each side) when holding similarly sized buys and sells positions. While the inclusion of financing costs does not lend CFDs to the formation of zero investment arbitrage portfolios, pairs trading is often touted as a strategy for CFD investors (e.g. Dunn, 2009). As such, it is important to take into account financing costs for the buys minus sells portfolio. Note also that by estimating the after financing cost performance for buys and sells portfolios separately, we may be overestimating financing costs as some buy and sell trades may be made by the same investor on the same day may cancel.

An interesting feature of CFD financing costs is that it is 'prepaid' if the position remains open at the market's close, rather than on the next trading day. As such, if an investor holds a long position at Friday's close and the next trading day is Monday, he will pay three days' worth of financing costs at Friday's close. Thus, we calculate the CFD financing charge, $F_{\boldsymbol{\delta}, t}$, as:

$$
F_{\delta, t}=\sum_{t=0}^{h} \frac{\left(R_{f, t}+\delta \times 0.015\right) d}{\text { days in year }}
$$

where $R_{f, t}$ is the RBA's overnight cash rate, $\delta$ takes the value of 1 for the buy portfolio and -1 for the sell portfolio and $d$ is the number of days between the current trading day and the next trading day. $F_{\delta, t}$ is calculated separately and subtracted from the buy and sell portfolios.

\section{Results}

\subsection{Bid-Ask Spreads of CFD Trades vs. the Underlying Stocks}

As we identify investor trades as those using buyer or seller initiated trades, they must always incur the bid-ask spread cost. The bid-ask spread is implicitly captured in our holding period return measures as we measure returns from the initiated trade, rather than the settlement price. As such, we first explicitly measure the bid-ask spreads of CFD trades to investigate the magnitude of trading costs. Panel A of Table 2 reports the average daily effective percentage spreads of the 
investor buy, sell and buys minus sells portfolios for CFDs as well as for the underlying stocks. Buys and sells incur only the effective half-spread while the 'Buys-Sells' portfolio combines both spreads as if the buys and sells portfolios were traded concurrently.

[Insert Table 2 Here]

CFD buys (sells) incur half-spread costs of $0.0964 \%$ (0.0973\%), while the underlying stocks on average incur lower spreads of $0.0796 \%(0.0799 \%)$. The bid-ask spread difference between the CFDs and underlying stocks is statistically significant at the $1 \%$ level. The total CFD spread of $0.1936 \%$ is also substantially lower than the average $0.7293 \%$ spread that Brown et al. (2010) report. This discrepancy can be attributed to the time-weighted spreads employed in Brown et al. (2010), which may be wider due to a lack of liquidity over the day. Further, their sample ends in December 2008 - a period in which CFD spreads were unusually high. As such, it appears that investors do attempt to trade CFDs when spreads are narrower.

\subsection{Investor Market Order Trade Performance Before Financing Costs}

For individuals to show stock picking ability in CFDs, the CFDs that they buy must outperform the market while the stocks that they sell underperform the market. In addition, the stocks that they buy must also statiscally outperform the stocks that they sell.

Panel B of Table 2 reports the daily average return of investor buy and sell trade portfolios for holding periods up until the day's settlement price, next day, week, month, half-year and year, inclusive of the bid-ask spread but before financing costs.

We find evidence that investor buys minus sells trades outperform after one day, but not for all other holding periods. For trades to the settlement price, we find that buys outperform sells by 2.16 basis points per day, although this is weakly statistically significant with a $t$-statistic of 1.54 . Following the next day, buy trades outperform sell trades by 5.85 basis points per day, which is statistically significant at the 5\% level, and suggests that investors have some intraday and daily stock picking ability. The stock picking ability appears to be concentrated in buy trades, with the 
buy trade portfolios after one day earning 10.12 basis points per day above the market return (statistically significant at the $5 \%$ level). Note that while 5.85 basis points per day may seem trivial, it amounts to an annualised return of $16.01 \% .{ }^{16}$ If we further assume a $20 \%$ margin on opening CFD positions separately for buy and sell positions (and therefore $20 \%$ margin on each side), this amounts to a $40.02 \%$ gain per year. These estimates, however, are before financing costs and brokerage (which we consider in the next section).

For intervals beyond one day, however, buy returns are not statistically different to sell returns. In particular, for monthly intervals and above, buys actually underperform sells - although the return is statistically insignificant. It is also interesting to note that buy portfolios held at halfyear and year holding periods earn $2.51 \%$ and $3.67 \%$, respectively, above the S\&P/ASX 200 market return (statistically significant at the $1 \%$ level), which suggests stock picking ability for buy portfolios. However, their respective sell portfolios earn even higher and statistically significant returns of $2.62 \%$ and $3.70 \%$ above the market. This suggests that CFDs sold earn above market returns and, therefore, have poor selling ability.

\subsection{Investor Market Order Trade Performance After Financing Costs}

A further consideration in CFD trading is financing costs, which will make buy trades perform worse and sell trades perform better. Financing costs will also negatively (positively) affect the buy (sell) portfolio more for longer holding periods as the financing costs are incurred on a daily basis. As such, while we find poor stock picking ability in sell trades over half-year and year holding periods, financing costs earned on sell trades may improve this result. Panel C of Table 2 reports the performance of investors after incorporating financing costs. The settlement price holding period results are the same as those in Panel B of Table 2, as financing costs are not incurred intraday and are reported for completeness.

We find that the buys minus sells portfolios across all holding periods are weaker than our

${ }^{16}(1.000585)^{254}-1=0.1601$. 
before-cost results, with the outperformance at the day holding period no longer statistically significant. At the month, half-year and year holding periods, the buys minus sells portfolios are negative and statistically significant after accounting for financing costs. This is due to the $1.5 \%$ OIC that both buy trades and sell trades incur - increasing the month, half-year and year holding period losses by $0.25 \%, 1.5 \%$ and $3 \%$, respectively.

Considering the buy and sell portfolios separately, we find that the financing costs which the buy portfolio incurs results in the holding period return of one month or longer being negative and statistically significant. At the daily holding period, the buy outperformance remains positive, although this result is statistically weaker than in the earlier results prior to financing costs. For the sell portfolio, the financing costs that are incurred are not sufficient in making the portfolios statistically outperform the market (i.e. negative excess market returns). For example, at the halfyear holding period, the return is $1.02 \%$ above the market (at the $1 \%$ significance level), while the year holding period return is $0.72 \%$ above the market and is statistically insignificant. Returns for the month holding period and below are also statistically insignificant.

For robustness, we also document the after financing cost performance using alternative market benchmarks in Appendix 2. Panel A in Appendix 2 uses the value-weighted return of the underlying stocks of the CFDs and the characteristic-based alphas following Pinnuck (2003) in Panel B. The buys minus sells portfolio results are consistent with Panel C of Table 2. With the exception of the Pinnuck alpha, the week holding period return is also negative and statistically significant at the $1 \%$ level. The benchmarks, however, differ in their attribution of losses. The Pinnuck alpha attributes losses to the positive and statistically significant alpha of the sell portfolios for the half-year and year holding period, while the underlying stock benchmark attributes losses to the underperforming buy portfolios.

While the positive and statistically insignificant short term performance, after financing costs, appears unremarkable, it compares favourably to the negative and statistically significant returns of individual investor market orders found in prior literature. For example, Linnainmaa 
(2010) finds Helsinki Stock Exchange individual investor market order returns from transaction price to the closing price of $-0.361 \%$ (statistically significant at the $1 \%$ level) while Fong et al. (2013) report market order discount retail broker trades on the ASX earning $-0.307 \%$ (statistically significant at the $1 \%$ level) using the same holding period.

Overall, we find that after financing costs and across holding periods of longer than a month, CFD market order investors experience negative trading performance with sell portfolio financing costs insufficient in allowing the trades to outperform the market.

\subsection{The Performance of Small vs. Large Market Order Trades}

In this section, we investigate whether smaller trades exhibit poor trading performance relative to larger trades. In the absence of algorithmic trading to break up trades in the CFD market, we expect that if investors are less sophisticated, they would tend to place smaller trades in the hopes of larger returns, akin to lotteries (e.g. Kumar, 2009). Consequently, we expect to see that smaller trades exhibit poor performance relative to larger trades.

In order to investigate whether small trades perform more poorly, we first separate individual trades into three trade size groups and then measure performance using the buys minus sells portfolio methodology. The trade size groups are in three broader groups than those used in Panel B of Table 1: less than $\$ 10,000$ (group 1), greater than $\$ 10,000$ and less than or equal $\$ 20,000$ (group 2) and greater than $\$ 20,000$ (group 3). The broader groups ensure adequate trades are present in all groups daily and in recognition that margins in CFDs mean investor capital requirements are fewer than with share trading. For example, a trade size group 1 trade of $\$ 5,000$ would require at most $20 \%$ or $\$ 1,000$ up-front in margins.

Table 3 reports investor performance, after financing costs, for the trade size groups. We find that for small trades (group 1), the buys minus sells portfolio incur positive and statistically significant returns after one day (10\% significance level). Mid-sized trades are the worst performing group, with negative and statistically significant buys minus sells portfolio returns after one week 
(10\% significance level). In contrast, large trade groups exhibit positive and statistically significant buys minus sells returns at the settlement day and after one week (10\% level). Across all groups, buys minus sells portfolio returns are negative and statistically significant at the half-year and year holding period, which suggests that financing costs are a significant factor for trading in the medium term. In unreported results, we also find that the return difference of buys minus sells portfolios between small and large trades are not statistically significant across all holding periods. This suggests that the superior performance at the settlement day and daily holding period inTable 2 Panel B of Table 2 is mainly driven by small and large trades. Our results are therefore inconsistent with small trades being used by unsophisticated investors, but consistent with large trades being made by more sophisticated investors.

[Insert Table 3 Here]

\subsection{CFDs vs. Underlying Stock Market Order Trade Performance}

Another method of determining the performance of market order CFD trades is to compare their buys minus sells market order trade performance with that of market order trades on the underlying stock. It should be noted that the underlying stock predominantly consists of institutional trading, as ASX-listed CFDs are derivatives of the largest stocks on the ASX. Indeed, Fong et al. (2013) shows that purely institutional brokers on the ASX dominate trading in the top 50 stocks and $51^{\text {st }}$ to $300^{\text {th }}$ largest stocks with a turnover market share of $63.7 \%$ and $54.2 \%$, respectively. ${ }^{17}$ In addition, and as noted prior, the underlying stocks also have lower spreads further reducing trading costs compared with CFDs. These factors may allow market orders on the underlying stock to perform better than trades on CFDs.

Table 4 reports the buys minus sells portfolio market order trade performance before financing costs of CFDs compared with the underlying stocks. Panel A reports raw returns ${ }^{18}$ while Panel B reports the Pinnuck alphas. We only compare before financing cost (but after bid-ask

\footnotetext{
${ }^{17}$ If we include mixed brokers - those that service both retail and institutional investors - the shares increase to $91.4 \%$ and $87.8 \%$, respectively.

${ }^{18}$ There is no need to use a market benchmark as the buys minus sells portfolio cancels out the market return.
} 
spread) performance as we do not know the financing costs of investors in the underlying stocks. Our buys minus sells results in Panel A of Table 4 for CFDs are the same as those reported in Panel B (column 4) of Table 2.

In comparison to CFD trades, underlying market order trades perform for up to a one week holding period for both benchmarks. As can be seen in Panel A of Table 4, the market order trades for the underlying stocks earns -19.98 basis points from the trade to settlement price and the losses slightly lower to -26.32 basis points at the year holding period - both statistically significant at the 1\% level. Using Pinnuck alphas in Panel B, the losses are nearly monotonically declining with increasing holding periods and are statistically significant with the exception of the year holding period, where the alpha of -6.07 basis points is statistically insignificant. These results indicate that market order trades in the underlying stock earn negative returns due to the bid-ask spread on the trading day. This loss is not recovered for up to at least the year holding period using raw returns, though they are recovered at the year holding period based on the Pinnuck alpha.

When we compare the difference in returns between CFDs and the underlying stock in the 'CFDs-Underlying' column in Panel A of Table 4, we find that CFD trades outperform the underlying stocks from trade to settlement price by 22.14 basis points (statistically significant at the $1 \%$ level). This outperformance persists for at least one week and becomes statistically insignificant using longer holding periods for both return measures. Our findings suggest that CFD investors have better trade performance than their counterparts in the underlying stocks, despite wider spreads and a seeming lack of institutional investor participation. Further, the main driver of investor underperformance in the underlying stock is the bid-ask spread. In contrast, CFD investors are able to recuperate the bid-ask spread through better performance. These results, therefore, provide further evidence that the average investor in CFDs is actually better than the average investor in the same underlying stocks.

\section{[Insert Table 4 Here]}

\subsection{Market Timing}


While the above results show that investors have no positive trading performance after financing costs, except at the intraday or daily holding period, this section investigates whether investors are instead market timing trades by buying or selling prior to market upturns or downturns. For example, on a given day, CFD investors may be bullish by net buying high beta stocks while on another day be bearish by selling high beta stocks and/or buying low beta stocks.

In order to measure everyday market timing returns, we calculate the past year's market capital asset pricing model (CAPM) beta as a proxy for the underlying stock's market loading, noting that buy trades have a positive beta exposure while sell trades have a negative beta exposure. We then calculate the daily aggregate beta as the trade value-weighted beta for all trades. The daily aggregate beta is then multiplied with the market (S\&P/ASX 200 Accumulation Index) return over the subsequent day, week, month, half-year or year holding periods to calculate the market timing returns. We then calculate the excess market timing return as the market timing return less the riskfree rate using the RBA's overnight cash rate as the proxy.

Formally, the daily excess market timing return at a given holding period $h$ is expressed as:

$$
\operatorname{EMT}_{t}^{h}=\sum_{i=1}^{n} \frac{\operatorname{NetVol}_{i, t} \times P_{i, t} \times \beta_{i, t}}{\sum_{i=1}^{n}\left|\operatorname{NetVol}_{i, t}\right| \times P_{i, t}} R_{m, t}^{h}-R_{f, t}^{h}
$$

where $\beta_{i, t}$ is stock $i$ 's market beta estimated using the past year's stock and market return (S\&P/ASX 200 Accumulation Index). $R_{f, t}^{h}$ is the risk-free rate return over holding period $h$ using the RBA's overnight cash rate.

Table 5 reports our excess market timing results, before and after financing costs, across the different holding periods. In unreported results, we find an average daily CFD trade-weighted beta of investors of -0.067 ( $t$-stat of -3.88$)$ over the sample period. This suggests that investor market order trades, on average, were slightly short the market. Before costs, returns across all holding periods earn below the risk-free rate, however, this is only statistically significant at the half-year and year holding periods at the $1 \%$ significance level. After incorporating financing costs, holding period returns are more negative and have stronger statistical significance from the monthly period 
onwards. For example, after financing costs, investors earn a monthly holding period return $0.29 \%$ below the risk-free rate (statistically significant at the 5\% level), and a year holding period return $4.92 \%$ below the risk-free rate per year (statistically significant at the $1 \%$ level). These results suggest that investors are poor market timers in the medium term, even before financing costs. Moreover, we find no evidence of market timing skill at shorter intervals.

\section{[Insert Table 5 Here]}

\subsection{Investor Dollar Profits}

This section investigates the dollar profits earned by investors. Our prior results using returns-based measures found that individuals show some evidence of stock picking ability at the intraday and daily holding periods. There are, however, some shortcomings in using trade-based buys minus sells percentage return measures. First, the return measures do not take into account the net positions held overnight, but instead assume that trades are closed within plausible holding periods that a CFD investor would use. Indeed, we do not have information about when a particular investor closes their position. Second, percentage return measures mask the fact that each day will have different trading volumes. For example, if investors earn large negative returns on high trading volume days and earn large positive returns on low trading volume days, the daily average return would be close to zero despite an average daily loss in dollar terms. ${ }^{19}$ A similar argument may be made with buy and sell trade portfolios not being of equal size every day. Subsequently, the buys minus sells percentage portfolio return may not be an accurate reflection of the actual gains and losses to investors.

To overcome these two problems, we measure trading dollar profits, dollar profits of overnight positions held and their related dollar financing costs. This is possible given our sample period begins when share CFDs are introduced, and therefore we can estimate the net positions which remain open daily. While investors may be able to close positions using the exchange for physical (EFP) facility, we consider the EFP volumes traded during our sample period from the

\footnotetext{
${ }^{19}$ Moeller et al. (2005) make a similar point with the very large dollar losses of bidder company stock returns following acquisitions in 2000-2001, despite the abnormal percentage returns being relatively small to other years.
} 
ASX EFP website ${ }^{20}$ and find no occurrences of EFP trades on share CFDs.

We calculate the dollar trading profits in three parts: the mark-to-market profits of trades on the day to the day's close, the mark-to-market profits of positions held overnight to the day's close and financing costs of positions held overnight. As per the returns-based measures, investor trades are identified as those that are buyer or seller initiated. Formally, the total daily profits are calculated as:

$$
\begin{aligned}
\text { Total Dollar Profit } t= & \sum_{x=1}^{z} \text { TVol }_{i, x, t}\left(P_{i, t}-P_{i, x, t}\right)+\sum_{n=1}^{i} \text { OVol }_{i, t-1}\left(P_{i, t}-P_{i, t-1}\right)- \\
& \sum_{n=1}^{i} \text { OVol }_{i, t} \times P_{i, t}\left(R_{f, t}+\delta \times 0.015\right) d_{t} / \text { days in year }
\end{aligned}
$$

where $T \mathrm{Vol}_{i, x, t}$ is the signed volume in trade $x$ for stock $i$ and $O V o l_{i, t-1}$ is the overnight signed volume of positions held in stock $i$ on the prior trading day (adjusted for capitalisation adjustments on day $t$ ). The first term in the right hand side of equation 6 measures the mark-to-market profits of the daily trades; the second term measures the mark-to-market profits of overnight positions; and the third term measures financing costs of overnight positions as used in equation 4.

We report the daily dollar profits of investors in Table 6 , as well as the average daily value traded and total overnight positions held separately for buys and sells (trades or net overnight positions). We find positive and statistically significant mark-to-market profits for the daily trades and financing costs, however, profits from overnight positions and total profit is not statistically different to zero. The average daily trade value is slightly larger for sells of $\$ 3.31$ million compared with buys of $\$ 3.09$ million. The higher daily sell trades contributes to the much larger daily average net sell positions held by investors of $-\$ 120.88$ million compared with net buy positions of $\$ 11.70$ million. The large net sell positions also contribute to the positive total financing costs earned of $\$ 12,664$ per day.

\section{[Insert Table 6 Here]}

In comparison, total mark-to-market trade profits are modest, with sell trades earning $\$ 1,816$

\footnotetext{
${ }^{20} \mathrm{http}: / /$ www.asx.com.au/products/exchange-for-physicals.htm.
} 
per day (statistically significant at the 5\% level) and buy trades of $\$ 1,497$ per day (statistically significant at the $10 \%$ level). This suggests that investors are able to consistently make positive mark-to-market dollar profits daily in both buys and sells, in contrast to the statistically insignificant trade to settlement price holding period returns of buys and sells in Panel B of Table 2. The total mark-to-market trade dollar profit of $\$ 3,312$ is statistically significant, but not economically significant. If we consider that, on average, $\$ 6.41$ million of trade value per day is used to generate the profits, this equates to a return of 5.17 basis points - about half of the conservative brokerage rate of 10 basis points. This suggests that investors are unable to profit from intraday trading alone. Mark-to-market positions comprise the bulk of profits, totalling $\$ 14,996$ per day. However, this is not statistically significant despite being economically more substantial than trade profits. We investigate the reason for the lack of statistical significance by calculating the daily cumulative profits of the three sources in Figure 1. As shown, mark-to-market trade profits and financing costs accumulate smoothly over time, with financing costs earning more than mark-to-market daily trade profits. Cumulative mark-to-market profits of overnight positions, however, peak in November 2008 at about $\$ 50.5$ million and return to nearly zero at the sample period's end. The large, and subsequent disappearance of, profits is due to the net sell dollar positions held overnight, as shown in 
Figure 2.

[INSERT FIGURE 1 HERE]

[INSERT FIGURE 2 HERE]

Figure 2 plots the net daily positions held by investors against the cumulative S\&P/ASX 200 Accumulation Index. Net sell positions accumulate immediately from the introduction of CFDs and proceed to accumulate until September 2008. The net sell positions combined with a sharp fall in stock returns, due to the global financial crisis during this period, contribute to the large cumulative profits of overnight positions (Figure 1). The reductions in net sell positions after September 2008 is explained by the short sales ban from 22nd September 2008 to 19th November 2008 for all stocks, and from 22nd September 2008 to 22nd May 2009 for select financial stocks (see Do et al., 2012). After the short sale ban is lifted, investors continue to accumulate short positions, with the rising market subsequently driving cumulative overnight position profits to zero. ${ }^{21}$ In summary, investors appear to be using CFDs as a means to short stocks, as evidenced by the consistently large net positions, positive trading profits and financing costs earned.

\section{Conclusion}

CFDs have become increasingly popular with individual investors. However, some regulators and academic literature identify individual investors as being susceptible to trading losses in financial markets due to a lack of investor sophistication. Given the leverage and complexity of derivatives such as CFDs, these losses may be magnified.

We find that ASX-listed CFD market order buy trades outperform their sell trades over a one day holding period, inclusive of the bid-ask spread. This short term outperformance is contained in both small and large trades, even after financing costs. CFD market trades also statistically outperform the market trades on underlying stocks of up to a week holding period -

\footnotetext{
${ }^{21}$ In unreported results, we also look at the net positions held overnight in S\&P/ASX 200 CFDs (ASX ticker 'IQ') and find consistent but more gradual net sell positions held over the same sample period, with the exception of no reduction in net sell positions during the short sale ban and net buy positions on the last few days of the sample period.
} 
suggesting that CFD investors exhibit better trade performance than the average market order trade. The short term outperformance, however, is not economically significant and would not cover conservative brokerage estimates of ten basis points. At longer holding periods from one month to one year, investors earn negative returns due to financing costs rather than poor stock selection ability.

In our analysis of the market timing ability of trades, we find that investors cannot beat the risk-free rate before or after financing costs. Further, consistent investor holdings of large net sell positions suggest that investors use CFDs for their shorting ability, which would be difficult strategy for individual investors to in the underlying market. We conclude that investors using market orders on ASX-listed share CFDs display some short term trading performance, which is inconsistent with the poor performance of individual investors found in prior literature.

Finally, a caveat should be made on our use of the ASX-listed CFD sample and whether we may generalise our findings to OTC markets (where regulators are displaying greater concern for investor welfare). It is possible that since ASX-listed CFDs are a fairly recent innovation, only the more sophisticated investors are currently trading them. Therefore, as the ASX-listed CFD market matures, we may find the performance of trades being similar to that found of investors trading ASX shares or trading in other stock markets around the world. Indeed, using the CFD trades from an OTC provider is the most direct method of studying the performance of individuals trading OTC CFDs and, therefore, remains an important area for future research.

\section{References}

ASIC, 2010a, Report 205: Contracts for difference and retail investors. Available at: http://www.asic.gov.au/asic/pdflib.nsf/LookupByFileName/rep205.pdf/\$file/rep205.pdf.

- 2010b, Thinking of trading contracts for difference (CFDs)? Available at: https://www.moneysmart.gov.au/media/173820/thinking-of-trading-in-contracts-fordifference-cfds.pdf. 
—, 2011, Regulatory guide 227: Over-the-counter contracts for difference: Improving disclosure for retail investors. Available at: http://www.asic.gov.au/asic/pdflib.nsf/LookupByFileName/RIS-rg227-1.pdf/\$file/RISrg227-1.pdf.

Australian Tax Office, 2005, Income tax: Tax consequences of financial contracts for differences. Available at: http://law.ato.gov.au/pdf/pbr/tr2005-015.pdf.

Barber, B. M., and T. Odean, 2000, Trading is hazardous to your wealth: The common stock investment performance of individual investors, Journal of Finance 55, 773-806.

Barber, B. M., Y.T. Lee, Y.J. Liu, and T. Odean, 2009a, Just how much do individual investors lose by trading? Review of Financial Studies 22, 609-632.

Barber, B. M., T. Odean, and N. Zhu, 2009b, Do retail traders move markets? Review of Financial Studies 22, 151-186.

Bauer, R., M. Cosemans, and P. Eichholtz, 2009, Option trading and individual investor performance, Journal of Banking and Finance 33, 731-746.

Brown, C., J. Dark, and K. Davis, 2010, Exchange traded contracts for difference: Design, pricing, and effects, Journal of Futures Markets 30, 1108-1149.

Cacciotti, D., and D. Michayluk, 2012, How do exchange-traded contracts for difference affect the underlying market?, Working paper (Finance Discipline Group, University of Technology, Sydney).

Chen, H.L., N. Jegadeesh, and R. Wermers, 2000, The value of active mutual fund management: An examination of the stockholdings and trades of fund managers, Journal of Financial and Quantitative Analysis 35, 343-368.

Do, B., V. Do, and D. Chai, 2012, Does the 2008 short sale ban affect the enforcement of the law of one price? Evidence from Australia, Accounting and Finance 52, 117-144.

Dunn, J., 2009, Pairs trading the no.1 strategy for CFD traders. Available at: http://www.thebull.com.au/experts/articles_detail.php?id=5821. 
Ellis, K., R. Michaely, and M. O'Hara, 2000, The accuracy of trade classification rules: Evidence from Nasdaq, Journal of Financial and Quantitative Analysis 35, 529-551.

Fong, K. Y. L., D. R. Gallagher, and A. D. Lee, 2013, Individual investors and broker types, Journal of Financial and Quantitative Analysis (forthcoming).

Foster, F. D., and W.M. Liu, 2011, Options on options, tradeoffs, technology and algorithms: My how times have changed, Working paper (Research School of Business, Australian National University).

Goettler, R. L., C. A. Parlour, and U. Rajan, 2009, Informed traders and limit order markets, Journal of Financial Economics 93, 67-87.

Griffin, J. M., J. H. Harris, and S. Topaloglu, 2003, The dynamics of institutional and individual trading, Journal of Finance 58, 2285-2320.

Henker, T., and J.-X. Wang, 2006, On the importance of timing specifications in market microstructure research, Journal of Financial Markets 9, 162-179.

Hollifield, B., R. A. Miller, P. Sandås, and J. Slive, 2006, Estimating the gains from trade in limitorder markets, Journal of Finance 61, 2753-2804.

Hvidkjaer, S., 2008, Small trades and the cross-section of stock returns, Review of Financial Studies $21,1123-1151$.

Investment Trends, 2010, Annual CFD report (Investment Trends Pty Ltd, Sydney, Australia).

Kumar, A., 2009, Who gambles in the stock market? Journal of Finance 64, 1889-1933.

Linnainmaa, J. T., 2010, Do limit orders alter inferences about investor performance and behavior? Journal of Finance 65, 1473-1506.

Menkhoff, L., C. L. Osler, and M. Schmeling, 2010, Limit-order submission strategies under asymmetric information, Journal of Banking and Finance 34, 2665-2677.

Moeller, S. B., F. P. Schlingemann, and R. M. Stulz, 2005, Wealth destruction on a massive scale? A study of acquiring-firm returns in the recent merger wave, Journal of Finance 60, 757782. 
Noble, A., 2010, Taxation treatment of CFDs. Available at: http://www.asx.com.au/documents/products/taxation_of_cfds_nov_2010.pdf.

Oh, N. Y., J. T. Parwada, and T. S. Walter, 2008, Investors' trading behavior and performance: Online versus non-online equity trading in Korea, Pacific-Basin Finance Journal 16, 26-43.

Pinnuck, M., 2003, An examination of the performance of the trades and stock holdings of fund managers: Further evidence, Journal of Financial and Quantitative Analysis 38, 811-828.

Rhode, W., 2010, Centrally cleared CFDs: The buy-side perspective (Tabb Group, London, United Kingdom).

Roşu, I., 2009, A dynamic model of the limit order book, Review of Financial Studies 22, 46014641. 
Table 1

\section{Descriptive Statistics}

This table reports descriptive statistics of the daily dollar trading volumes and the average daily dollar trade sizes for all ASX-listed share CFDs and their underlying stocks from 5 November 2007 to 30 June 2010. Statistics for a selection of individual share CFDs and their underlying stock are also reported. Only underlying stock trades that were made during continuous trading hours are included in order to match CFD trading hours. Panel A reports statistics for trade volume and size. Panel B reports the percentage distribution of trades by trade count and trade size in dollar-valued trade size groups separately for all CFDs and all underlying stocks.

\begin{tabular}{|c|c|c|c|c|c|c|}
\hline \multicolumn{7}{|c|}{ Panel A. Daily Trading Volume and Average Daily Dollar Trade Size Statistics } \\
\hline & \multicolumn{3}{|c|}{ Daily Dollar Trading Volume (\$'000s) } & \multicolumn{3}{|c|}{ Average Daily Dollar Trade Size } \\
\hline & Mean & Median & Std & Mean & Median & Std \\
\hline All CFDs & 7,798 & 7,351 & 3,590 & 22,269 & 21,734 & 6,464 \\
\hline All Underlying Stocks & $2,983,671$ & $2,999,642$ & $1,028,553$ & 15,068 & 13,277 & 6,378 \\
\hline ANZ Bank (CFDs) & 321 & 225 & 335 & 20,972 & 18,659 & 12,106 \\
\hline ANZ Bank (Stock) & 157,237 & 148,058 & 74,706 & 17,854 & 15,744 & 7,311 \\
\hline BHP Billiton (CFDs) & 1,259 & 980 & 968 & 36,016 & 33,331 & 15,375 \\
\hline BHP Billiton (Stock) & 440,872 & 403,018 & 188,006 & 34,719 & 31,543 & 13,343 \\
\hline Cochlear (CFDs) & 129 & 85 & 127 & 23,514 & 17,979 & 19,354 \\
\hline Cochlear (Stock) & 13,943 & 12,392 & 7,290 & 3,482 & 3,222 & 1,218 \\
\hline Commonwealth Bank (CFDs) & 1,154 & 810 & 1,085 & 33,848 & 28,565 & 20,003 \\
\hline Commonwealth Bank (Stock) & 178,935 & 165,544 & 83,225 & 19,983 & 17,142 & 9,516 \\
\hline Foster's Group (CFDs) & 85 & 43 & 146 & 18,941 & 13,044 & 18,855 \\
\hline Foster's Group (Stock) & 41,853 & 36,036 & 27,845 & 14,828 & 13,269 & 8,117 \\
\hline Nufarm (CFDs) & 20 & 12 & 22 & 4,848 & 4,100 & 2,941 \\
\hline Nufarm (Stock) & 8,297 & 6,502 & 6,998 & 3,764 & 3,468 & 1,608 \\
\hline Rio Tinto (CFDs) & 677 & 463 & 640 & 24,629 & 22,668 & 14,717 \\
\hline Rio Tinto (Stock) & 187,727 & 163,193 & 106,929 & 22,154 & 17,969 & 12,489 \\
\hline Westpac (CFDs) & 258 & 171 & 268 & 22,458 & 19,681 & 12,869 \\
\hline Westpac (Stock) & 161,782 & 149,312 & 72,719 & 18,929 & 16,607 & 8,451 \\
\hline
\end{tabular}

Panel B. Percentage Distribution of Trades by Trade Count and Trade Value in Trade Size Groups

Trade Size Groups (Dollars)

\begin{tabular}{lrrrrr}
\hline & $0 \leq \mathrm{T} \leq 5,000$ & $5,000<\mathrm{T} \leq$ & $10,000<\mathrm{T} \leq$ & $20,000<\mathrm{T} \leq$ & $\mathrm{T}>50,000$ \\
& & 10,000 & 20,000 & 50,000 & 27.51 \\
\hline All CFDs (Trade Count \%) & 20.93 & 17.04 & 25.54 & 8.98 \\
All Underlying Stocks (Trade Count \%) & 60.19 & 14.12 & 11.58 & 9.07 & 5.04 \\
All CFDs (Trade Value \%) & 2.25 & 5.74 & 16.97 & 38.73 & 36.30 \\
All Underlying Stocks (Trade Value \%) & 5.87 & 6.93 & 11.15 & 19.06 & 56.99 \\
\hline
\end{tabular}


Table 2

\section{Investor Market Order Performance Before and After Costs}

This table reports the effective half spread and investor performance before and after financing costs in ASX-listed share CFDs across various holding periods from 5 November 2007 to 30 June 2010. Investor trades are identified as those trades which are buyer or seller initiated. We estimate the spread as the effective percentage half-spread, calculated as the absolute difference between the trade price less the midpoint of the prevailing bid and ask price over the midpoint bid-ask price. Buy and sell portfolios are then calculated based on the buy or sell trade value-weighted returns from the traded price to the settlement price, next day, month, half-year or year holding periods. Buy and sell portfolios are adjusted by the S\&P/ASX 200 Accumulation Index. Financing costs are the RBA's overnight cash rate plus $1.5 \%$ for buys and the RBA rate less $1.5 \%$ for sells. The financing costs are paid daily for buys and received daily for sells. Panel A reports the average trade -value weighted daily effective half-spread of CFDs and their underlying stocks for individual buy and sell portfolios. The 'Buys-Sells' column reports the combined spreads of the buy and sell portfolios. Panel B reports average daily investors' trade performance. Panel C reports average daily investors' trade performance after financing costs. $* * *, * *, *$ denote statistical significance at the $1 \%, 5 \%$ and $10 \%$ levels, respectively, using Newey-West $t$-statistics with six lags.

\section{Panel A. Average Effective-Half Spread of Buy and Sell Portfolios}

Average Daily Effective Half Spread (\%)

\begin{tabular}{llll}
\hline & \multicolumn{1}{c}{ Buy } & \multicolumn{1}{c}{ Sell } & Buys-Sells \\
\hline CFDs & 0.0964 & 0.0973 & 0.1936 \\
Underlying Stocks & 0.0796 & 0.0799 & 0.1595 \\
CFDs-Underlying & $0.0167^{* * *}$ & $0.0174 * * *$ & $0.0342^{* * *}$ \\
$t$-statistic & 3.16 & 3.70 & 3.46 \\
\hline
\end{tabular}

\begin{tabular}{|c|c|c|c|c|c|c|}
\hline \multicolumn{7}{|c|}{ Panel B. Investor Holding Period Returns } \\
\hline & \multicolumn{3}{|c|}{ Market Adjusted Holding Period Return (\%) } & \multicolumn{3}{|c|}{$t$-statistic } \\
\hline Holding Period & Buy & Sell & Buys-Sells & Buy & Sell & Buys-Sells \\
\hline Settlement Price & 0.0301 & 0.0085 & 0.0216 & 1.05 & 0.33 & 1.54 \\
\hline Day & $0.1012 * *$ & 0.0427 & $0.0585^{* *}$ & 2.31 & 1.05 & 2.00 \\
\hline Week & $0.1580^{*}$ & 0.1457 & 0.0123 & 1.68 & 1.62 & 0.23 \\
\hline Month & 0.0774 & 0.1255 & -0.0482 & 0.45 & 0.78 & -0.56 \\
\hline Half-Year & $2.5106 * * *$ & $2.6227 * * *$ & -0.1122 & 6.19 & 6.92 & -0.53 \\
\hline Year & $3.6720 * * *$ & $3.6924 * * *$ & -0.0204 & 5.73 & 6.38 & -0.09 \\
\hline \multicolumn{7}{|c|}{ Panel C. Investor Holding Period Returns after Financing Costs } \\
\hline & \multicolumn{3}{|c|}{ Market Adjusted Holding Period Return (\%) } & \multicolumn{3}{|c|}{$t$-statistic } \\
\hline Holding Period & Buy & Sell & Buys-Sells & Buys & Sells & Buys-Sells \\
\hline Settlement Price & 0.0301 & 0.0085 & 0.0216 & 1.05 & 0.33 & 1.54 \\
\hline Day & $0.0758 *$ & 0.0292 & 0.0466 & 1.73 & 0.72 & 1.59 \\
\hline Week & 0.0310 & 0.0781 & -0.0471 & 0.33 & 0.86 & -0.87 \\
\hline Month & $-0.4288 * *$ & -0.1428 & $-0.2860 * * *$ & -2.51 & -0.88 & -3.35 \\
\hline Half-Year & -0.5944 & $1.0208 * * *$ & $-1.6152 * * *$ & -1.49 & 2.77 & -7.65 \\
\hline Year & $-2.3128 * * *$ & 0.7170 & $-3.0298 * * *$ & -3.56 & 1.23 & -13.09 \\
\hline
\end{tabular}


Table 3

Investor Market Order Performance after Financing Costs by Trade Size Groups

This table reports the investor average daily holding period returns, after financing costs, in ASX-listed share CFDs across various holding periods from 5 November 2007 to 30 June 2010. Investor trades are identified as those trades which are buyer or seller initiated. Trades are separated into three trade size groups: less than $\$ 10,000$ (group 1), between $\$ 10,000$ and $\$ 20,000$ (group 2) and greater than $\$ 20,000$ (group 3). The size groups are nominal amounts. Buy and sell portfolios are then calculated based on the buy or sell trade value weighted return from the traded price to the settlement price, next day, month, half-year or year holding periods. Buy and sell portfolios are adjusted by the S\&P/ASX 200 Accumulation Index. Financing costs are the RBA's overnight cash rate plus $1.5 \%$ for buys and the RBA rate less $1.5 \%$ for sells. The financing costs are paid daily for buys and received daily for sells. ***, **, ${ }^{*}$ denote statistical significance at the $1 \%, 5 \%$ and $10 \%$ levels, respectively, using Newey-West $t$-statistics with six lags.

\begin{tabular}{llcccrrr}
\hline & \multicolumn{2}{c}{ Market Adjusted Holding Period Return (\%) } & \multicolumn{3}{c}{$t$-statistic } \\
\hline Trade Size Groups Holding Period & \multicolumn{1}{c}{ Buy } & Sell & Buys-Sells & Buy & Sell & Buys-Sells \\
\hline 1 (small trades) & Settlement Price & 0.0276 & -0.0387 & 0.0663 & 0.62 & -1.05 & 1.40 \\
& Day & $0.2906^{* *}$ & 0.1052 & $0.1854^{*}$ & 2.54 & 0.85 & 1.76 \\
& Week & $0.6525^{* *}$ & 0.4237 & 0.2287 & 2.10 & 1.28 & 0.95 \\
& Month & $1.615^{* *}$ & $1.8136^{* * *}$ & -0.1987 & 2.49 & 3.00 & -0.50 \\
& Half-Year & $5.5311^{* *}$ & $8.5185^{* * *}$ & $-2.9874^{* * *}$ & 2.39 & 3.73 & -2.62 \\
& Year & -0.1597 & 2.9195 & $-3.0792^{* *}$ & -0.06 & 1.04 & -2.26 \\
& Settlement Price & 0.014 & 0.0174 & -0.0034 & 0.28 & 0.35 & -0.07 \\
& Day & $-0.2423^{*}$ & -0.0307 & -0.2116 & -1.69 & -0.23 & -1.55 \\
& Week & -0.2322 & 0.2107 & $-0.4429^{*}$ & -0.68 & 0.63 & -1.84 \\
& Month & 0.0614 & 0.77 & -0.7086 & 0.09 & 1.24 & -1.59 \\
& Half-Year & -0.9246 & 2.1251 & $-3.0497 * *$ & -0.38 & 0.87 & -3.51 \\
& Year & $-7.6754^{* *}$ & -4.0773 & $-3.5981^{* * *}$ & -2.50 & -1.35 & -2.98 \\
3 (large trades) & Settlement Price & $0.0806^{* *}$ & 0.013 & $0.0677^{*}$ & 2.37 & 0.40 & 1.72 \\
& Day & 0.0317 & -0.0707 & 0.1024 & 0.32 & -0.69 & 1.16 \\
& Week & -0.0291 & -0.3634 & $0.3344^{*}$ & -0.10 & -1.19 & 1.76 \\
& Month & -0.4791 & -0.2647 & -0.2143 & -0.70 & -0.35 & -0.60 \\
& Half-Year & $-3.8011^{*}$ & -2.3884 & -1.4127 & -1.96 & -1.03 & -1.56 \\
& Year & $-12.245^{* * *}$ & $-8.1503^{* * *}$ & $-4.0947^{* * *}$ & -4.99 & -2.97 & -3.90 \\
\hline
\end{tabular}


Table 4

Investor Market Order Performance in CFDs versus Underlying Stocks

This table reports the buys minus sells return of the market trades of investors in CFDs compared with underlying stocks across various holding periods from 5 November 2007 to 30 June 2010. Investor market trades are identified as those trades which are buyer or seller initiated. Buys minus sells portfolios are then calculated based on the buys less sells trade value weighted returns from the traded price to the settlement price, next day, month, half-year or year holding periods. Daily average buys minus sells portfolios are reported using raw returns in Panel A, and characteristicbased alphas using the methodology of Pinnuck (2003) are reported in Panel B. ***,**,* denote statistical significance at the $1 \%, 5 \%$ and $10 \%$ levels, respectively, using Newey-West $t$-statistics with six lags.

\begin{tabular}{|c|c|c|c|c|c|c|}
\hline \multicolumn{7}{|c|}{ Panel A. Raw Returns } \\
\hline \multirow[b]{2}{*}{ Holding Period } & \multicolumn{3}{|c|}{ Buys-Sells Holding Period Raw Return (\%) } & \multicolumn{3}{|c|}{$t$-statistic } \\
\hline & CFDs & Underlying & CFDs-Underlying & CFDs & Underlying & CFDs-Underlying \\
\hline Settlement Price & 0.0216 & $-0.1998 * * *$ & $0.2214 * * *$ & 1.54 & -9.91 & 8.59 \\
\hline Day & $0.0585^{* *}$ & $-0.2028 * * *$ & $0.2613 * * *$ & 2.00 & -9.41 & 6.56 \\
\hline Week & 0.0123 & $-0.1918 * * *$ & $0.2041 * * *$ & 0.23 & -7.57 & 3.41 \\
\hline Month & -0.0482 & $-0.1983 * * *$ & 0.1501 & -0.56 & -6.07 & 1.63 \\
\hline Half-Year & -0.1122 & $-0.2781 * * *$ & 0.1660 & -0.53 & -4.62 & 0.75 \\
\hline Year & -0.0204 & $-0.2632 * * *$ & 0.2427 & -0.09 & -4.09 & 1.00 \\
\hline \multicolumn{7}{|c|}{ Panel B. Characteristic-Based Alpha following Pinnuck (2003) } \\
\hline & \multicolumn{3}{|c|}{ Buys-Sells Holding Period Alpha (\%) } & \multicolumn{3}{|c|}{$t$-statistic } \\
\hline Holding Period & CFDs & Underlying & CFDs-Underlying & CFDs & Underlying & CFDs-Underlying \\
\hline Settlement Price & 0.0216 & $-0.1998 * * *$ & $0.2214^{* * *}$ & 0.84 & -9.52 & 6.41 \\
\hline Day & 0.0200 & $-0.1971 * * *$ & $0.2170 * * *$ & -1.28 & -8.58 & 2.76 \\
\hline Week & -0.0536 & $-0.1905 * * *$ & $0.1369 * * *$ & -2.79 & -6.84 & 0.44 \\
\hline Month & $-0.1655^{* * *}$ & $-0.1948 * * *$ & 0.0293 & -0.76 & -2.44 & 0.32 \\
\hline Half-Year & -0.1223 & $-0.1743 * *$ & 0.0520 & -0.55 & -0.95 & -0.24 \\
\hline Year & -0.1366 & -0.0759 & -0.0607 & 0.84 & -9.52 & 6.41 \\
\hline
\end{tabular}


Table 5

Excess Market Timing Returns of Investor Market Orders in CFDs

The sample is ASX-listed share CFDs trades from 5 November 2007 to 30 June 2010. Investor trades are identified as those trades which are buyer or seller initiated. Every day, we first calculate the net volume bought or sold in a share CFD. We then measure the past year's market (CAPM) beta as a proxy of the stock's market loading. Stocks bought have a positive beta exposure while stocks sold have a negative beta exposure. We then calculate the daily aggregate beta as the net trade value-weighted beta of all stocks. The daily aggregate beta is then multiplied with the market (S\&P/ASX 200 Accumulation Index) return over the subsequent day, week, month, half-year or year holding periods to calculate the market timing return. We then calculate the excess market timing return as the market timing return less the risk-free rate. The table reports the average daily excess market timing return and excess market timing return after financing costs over the various holding periods. ***,**,* denote statistical significance at the $1 \%, 5 \%$ and $10 \%$ levels, respectively, using Newey-West $t$-statistics with six lags.

\begin{tabular}{lcccc}
\hline Holding Period & $\begin{array}{c}\text { Excess Market Timing Holding } \\
\text { Period Return (\%) }\end{array}$ & $\begin{array}{l}t \text {-statistic } \\
\text { Excess less Financing Costs (\%) }\end{array}$ & $t$-statistic \\
\hline Day & -0.0202 & -0.77 & -0.0247 & -0.94 \\
Week & -0.0212 & -0.33 & -0.0412 & -0.64 \\
Month & -0.2116 & -1.52 & $-0.2936^{* *}$ & -2.04 \\
Half-Year & $-1.4462^{* * *}$ & -4.21 & $-1.9948^{* * *}$ & -5.18 \\
Year & $-3.6165^{* * *}$ & -7.07 & $-4.9266^{* * *}$ & -7.97 \\
\hline
\end{tabular}


Table 6

Investor Daily Dollar Profits from Trades and Overnight Positions Held

This table reports the average daily total dollar profits of investors, average daily traded value and average daily overnight positions held in ASX-listed share CFDs from 5 November 2007 to 30 June 2010. Investor trades are identified as those trades that are buyer or seller initiated. Total dollar profits are further split into mark-to-market trade profits, mark-to-market overnight position profits and financing costs as per equation 6. Profits are also reported separately for buy or sell trades and buy or sell overnight positions. $* * *, * *, *$ denote statistical significance at the $1 \%$, $5 \%$ and $10 \%$ levels, respectively, using Newey-West $t$-statistics with six lags.

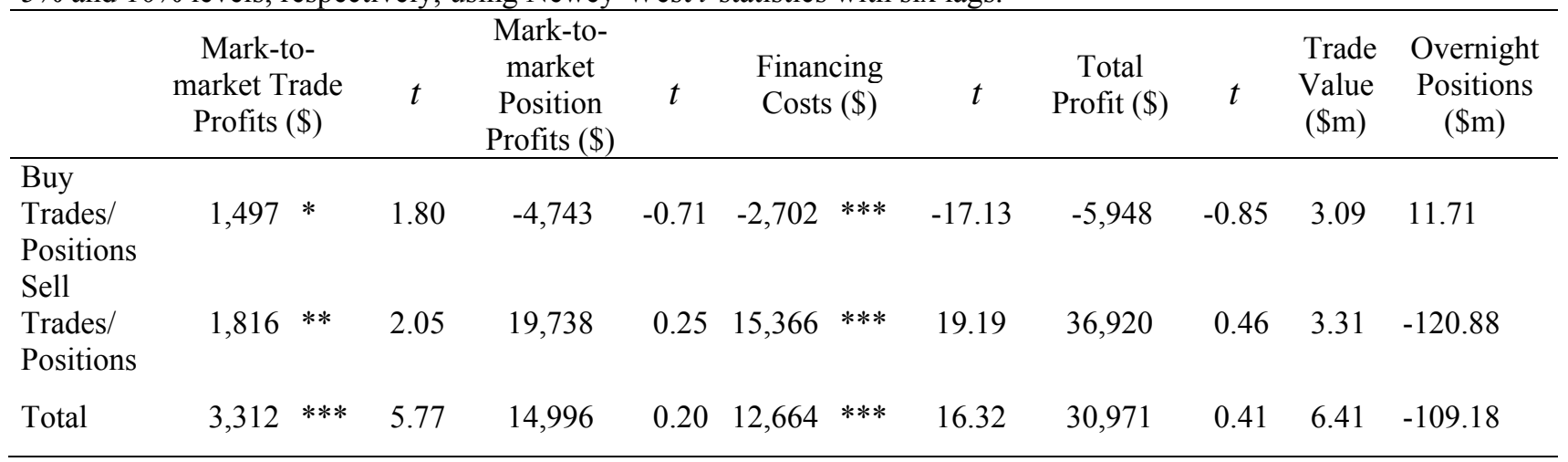


Figure 1

Cumulative Profits of Investor Market Orders ( $5^{\text {th }}$ November 2007 to $30^{\text {th }}$ June 2010)

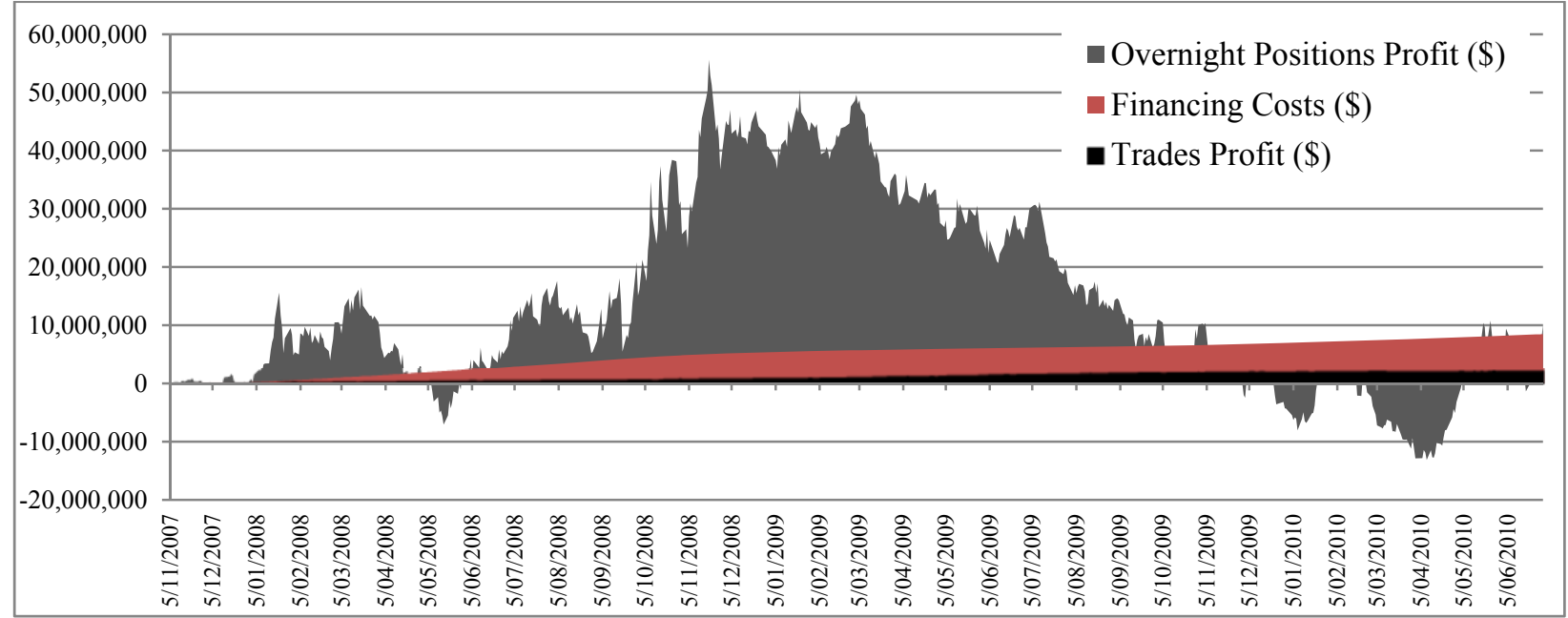


Figure 2

Net Dollar Positions Held Overnight by Investor Market Orders vs. Cumulative S\&P/ASX 200 Accumulation Index Return ( $5^{\text {th }}$ November 2007 to $30^{\text {th }}$ June 2010)

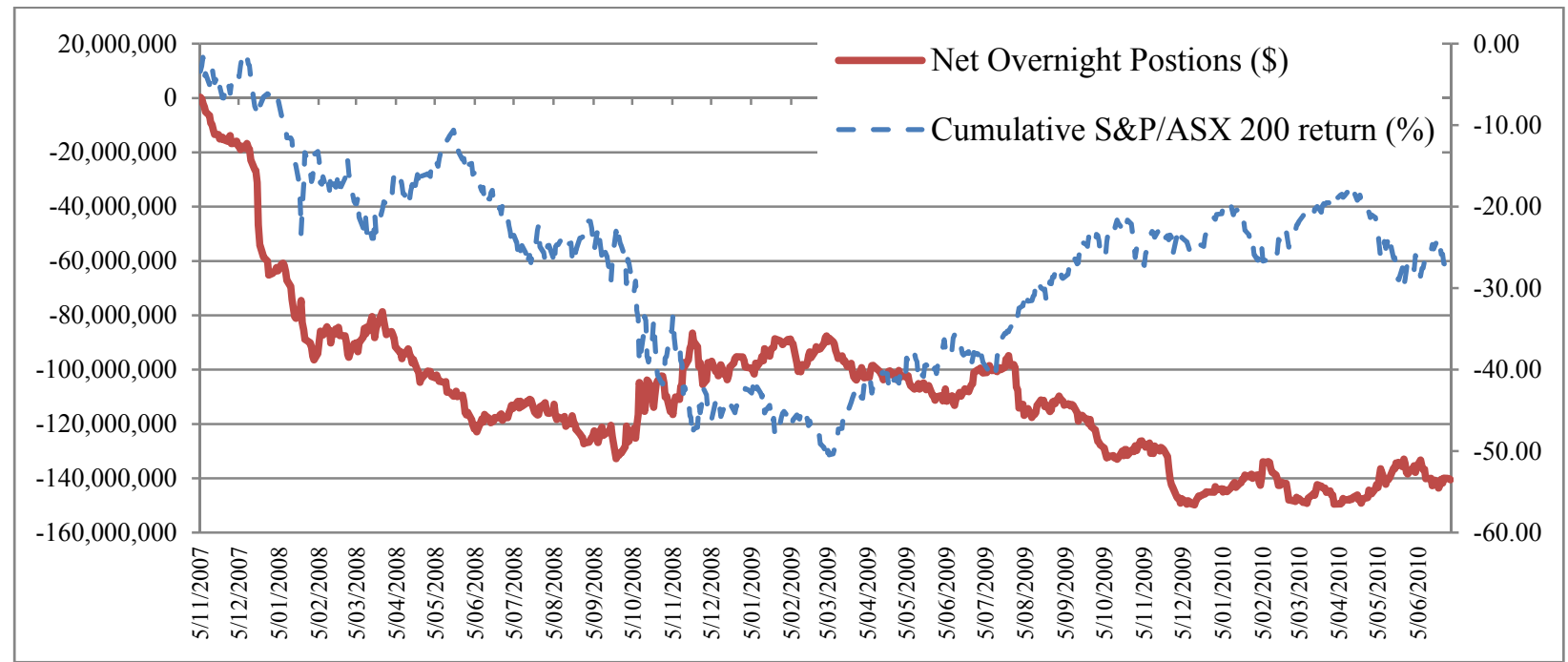




\section{Appendix 1}

\section{Quote Updating on CFDs versus Underlying Stock}

Every trading day from 5 November 2007 to 30 June 2010 for each ASX-listed share CFDs and their underlying stock we calculate the mean midpoint quote change in seconds, median midpoint quote change in seconds and the number of midpoint quote changes. The midpoint quote is the average of the best prevailing bid and ask quote at a given time. We then calculate the difference between the CFDs and underlying stock for each of the three daily measures and report in the table the daily time series average as $\Delta$ mean, $\Delta$ median and $\Delta$ nquotes respectively. The 'All Stocks' group is the time series average of the equally weighted average measures across all stocks each day. $* * *, * *, *$ denote statistical significance at the $1 \%, 5 \%$ and $10 \%$ levels, respectively, using $t$-statistics for $\Delta$ mean and $\Delta$ nquotes, while using the Wilcoxon signed-rank test statistic for $\Delta$ median.

\begin{tabular}{|c|c|c|c|c|c|c|c|c|c|}
\hline \multirow[b]{2}{*}{ Stocks } & \multicolumn{6}{|c|}{ CFDs less Underlying Stock Quotes } & \multicolumn{3}{|c|}{$p$-values } \\
\hline & $\begin{array}{c}\Delta \text { mean } \\
(\mathrm{sec})\end{array}$ & & $\begin{array}{c}\Delta \text { median } \\
(\mathrm{sec})\end{array}$ & & $\Delta$ nquotes & & $\Delta$ mean & $\Delta$ median & $\Delta$ nquotes \\
\hline All Stocks & 30.15 & $* * *$ & 12.16 & $* * *$ & -374.72 & $* * *$ & 0.00 & 0.00 & 0.00 \\
\hline AGL Energy & 5.34 & $* * *$ & 1.68 & $* * *$ & -220.26 & $* * *$ & 0.00 & 0.00 & 0.00 \\
\hline Alumina & 26.28 & $* * *$ & 7.69 & $* * *$ & -340.31 & $* * *$ & 0.00 & 0.00 & 0.00 \\
\hline Amcor & 6.31 & $* * *$ & 2.59 & $* * *$ & -59.66 & $* * *$ & 0.00 & 0.00 & 0.00 \\
\hline AMP & 39.99 & $* * *$ & 4.72 & $* * *$ & -163.98 & $* * *$ & 0.00 & 0.00 & 0.00 \\
\hline ANZ Bank & 11.69 & $* * *$ & 3.64 & $* * *$ & -155.39 & $* * *$ & 0.00 & 0.00 & 0.00 \\
\hline Asciano Group & 150.35 & & 26.77 & & -78.50 & & 0.34 & 0.50 & 0.34 \\
\hline AXA Asia Pacific & 3.64 & $* *$ & 1.62 & $* * *$ & -802.06 & $* * *$ & 0.02 & 0.00 & 0.00 \\
\hline BHP Billiton & 2.10 & $* * *$ & 0.73 & $* * *$ & -1342.56 & $* * *$ & 0.00 & 0.00 & 0.00 \\
\hline Bluescope Steel & 18.55 & $* * *$ & 9.27 & $* * *$ & -107.62 & $* * *$ & 0.00 & 0.00 & 0.00 \\
\hline Boral & 10.22 & $* * *$ & 3.09 & $* * *$ & -79.12 & $* * *$ & 0.00 & 0.00 & 0.00 \\
\hline Brambles Industries & 9.68 & $* * *$ & 2.42 & $* * *$ & -267.50 & $* * *$ & 0.00 & 0.00 & 0.00 \\
\hline CFD Retail Property & 119.02 & $* * *$ & 20.82 & & -30.00 & & 0.00 & 0.50 & 0.33 \\
\hline Coca-Cola Amatil & 1.07 & $* * *$ & 0.63 & $* * *$ & -173.48 & $* * *$ & 0.00 & 0.00 & 0.00 \\
\hline Cochlear & 103.43 & $* * *$ & 24.93 & $* * *$ & -153.68 & $* * *$ & 0.00 & 0.00 & 0.00 \\
\hline Commonwealth Bank & 3.93 & $* * *$ & 1.30 & $* * *$ & -124.08 & $* * *$ & 0.00 & 0.00 & 0.00 \\
\hline Computershare & 2.56 & & 0.54 & & -1091.50 & & 0.17 & 0.50 & 0.10 \\
\hline Crown & 10.67 & & 9.59 & $* * *$ & -1490.11 & $* * *$ & 0.23 & 0.00 & 0.00 \\
\hline CSL & 6.37 & & 1.69 & & -284.50 & $* *$ & 0.15 & 0.50 & 0.02 \\
\hline CSR & 23.00 & & 3.87 & & -96.50 & & 0.41 & 0.50 & 0.19 \\
\hline Dexus Property & 442.48 & & 62.18 & & -17.00 & & 0.25 & 0.50 & 0.15 \\
\hline Fairfax Holdings & 75.22 & $* * *$ & 17.77 & $* * *$ & -142.71 & $* * *$ & 0.00 & 0.00 & 0.00 \\
\hline Fortescue Metals & 12.74 & & 3.21 & & -87.00 & & 0.31 & 0.50 & 0.15 \\
\hline Foster's Group & 29.07 & $* * *$ & 6.55 & $* * *$ & -148.74 & $* * *$ & 0.00 & 0.00 & 0.00 \\
\hline GPT & 272.66 & $* * *$ & 178.72 & $* * *$ & -98.51 & $* * *$ & 0.00 & 0.00 & 0.00 \\
\hline Harvey Norman & 16.07 & & 5.45 & & -8.50 & & 0.55 & 0.50 & 0.68 \\
\hline Incitec Pivot & 25.31 & & 7.74 & & -13.00 & & 0.48 & 0.50 & 0.10 \\
\hline Insurance Australia Group & 21.11 & $* * *$ & 5.86 & $* * *$ & -100.34 & $* * *$ & 0.00 & 0.00 & 0.00 \\
\hline James Hardie & 4.30 & $*$ & 0.45 & & -930.50 & & 0.07 & 0.50 & 0.14 \\
\hline JB Hi-Fi & 17.02 & & 1.36 & & -474.50 & & 0.38 & 0.50 & 0.16 \\
\hline Leighton Holdings & 0.88 & $* * *$ & 0.33 & $* * *$ & -404.13 & $* * *$ & 0.00 & 0.00 & 0.00 \\
\hline Lend Lease & 7.19 & $* * *$ & 1.73 & $* * *$ & -187.34 & $* * *$ & 0.00 & 0.00 & 0.00 \\
\hline Lihir Gold & 29.22 & $* * *$ & 16.25 & $* * *$ & -38.01 & $* * *$ & 0.00 & 0.00 & 0.00 \\
\hline Macarthur Coal & 7.09 & & 1.57 & & -239.50 & & 0.33 & 0.50 & 0.18 \\
\hline Macquarie Bank & 1.59 & $* * *$ & 0.40 & $* * *$ & -707.78 & $* * *$ & 0.00 & 0.00 & 0.00 \\
\hline
\end{tabular}




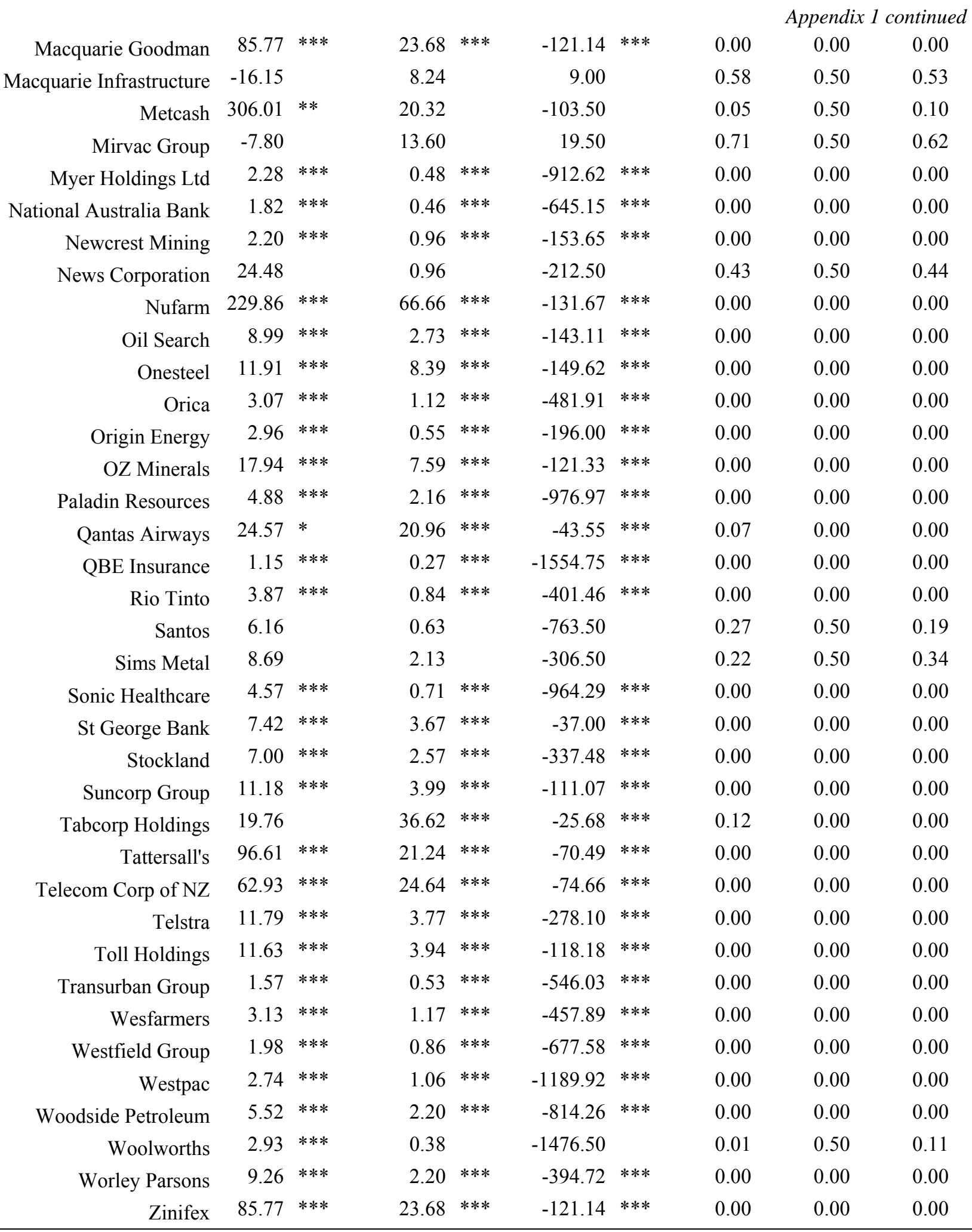




\section{Appendix 2}

Investor Performance after Financing Costs Using Alternative Benchmarking Specifications

The table reports investor performance after financing in ASX-listed share CFDs across various holding periods from 5 November 2007 to 30 June 2010 using alternative market benchmarks. Investor trades are identified as those trades which are buyer or seller initiated. Buys and sells portfolios are calculated based on the buy or sell trade value weighted return from the traded price to the settlement price, next day, month, half-year or year holding period. Panel A reports buys and sells portfolio returns adjusted by the value weighted return of all underlying stocks of the CFDs while Panel B reports characteristic-based alphas using the methodology of Pinnuck (2003). Financing costs are the RBA overnight cash rate plus $1.5 \%$ for buys and the RBA rate less $1.5 \%$ for sells. The financing costs are paid daily for buys and received daily for sells. $* * *, *, *$ denote statistical significance at the $1 \%, 5 \%$ and $10 \%$ levels, respectively using Newey-West $t$-statistics using six lags.

Panel A. Excess Value-Weighted CFDs Underlying Stock Return

\begin{tabular}{|c|c|c|c|c|c|c|}
\hline \multirow[b]{2}{*}{ Holding Period } & \multicolumn{3}{|c|}{ Adjusted Holding Period Return (\%) } & \multicolumn{3}{|c|}{$t$-statistic } \\
\hline & Buys & Sells & Buys-Sells & Buys & Sells & Buys-Sells \\
\hline Settlement Price & 0.0301 & 0.0085 & 0.0216 & 1.05 & 0.33 & 1.54 \\
\hline Day & 0.0619 & 0.0153 & 0.0466 & 1.45 & 0.38 & 1.59 \\
\hline Week & -0.0223 & 0.0248 & -0.0471 & -0.26 & 0.29 & -0.87 \\
\hline Month & $-0.6195 * * *$ & $-0.3336 * *$ & $-0.2860 * * *$ & -3.70 & -2.08 & -3.35 \\
\hline Half-Year & $-1.2712 * * *$ & 0.3440 & $-1.6152 * * *$ & -3.17 & 0.96 & -7.65 \\
\hline Year & $-3.3964 * * *$ & -0.3666 & $-3.0298 * * *$ & -5.66 & -0.69 & -13.09 \\
\hline \multicolumn{7}{|c|}{ Panel B. Characteristic-Based Alpha following Pinnuck (2003) } \\
\hline & \multicolumn{3}{|c|}{ Holding Period Alpha (\%) } & \multicolumn{3}{|c|}{$t$-statistic } \\
\hline Holding Period & Buys & Sells & Buys-Sells & Buys & Sells & Buys-Sells \\
\hline Settlement Price & 0.0301 & 0.0085 & 0.0216 & 1.05 & 0.33 & 1.54 \\
\hline Day & 0.0694 & 0.0613 & 0.0081 & 1.45 & 1.32 & 0.34 \\
\hline Week & 0.0708 & 0.1839 & $-0.1131 * * *$ & 0.64 & 1.61 & -2.69 \\
\hline Month & -0.1863 & 0.2170 & $-0.4033 * * *$ & -0.83 & 0.99 & -6.82 \\
\hline Half-Year & -0.1219 & $1.5035 * * *$ & $-1.6254 * * *$ & -0.28 & 3.92 & -10.17 \\
\hline Year & -0.2038 & $2.9422 * * *$ & $-3.1460 * * *$ & -0.27 & 4.00 & -12.70 \\
\hline
\end{tabular}

